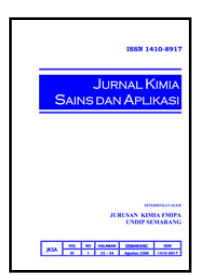

\title{
Pengaruh Variasi Rasio Si/Al pada Sintesis Zeolit dengan Metode Refluks
}

\author{
Muchamad Fadlulah $^{a}$, Sriatun ${ }^{\mathrm{a}^{*}}$, Abdul Haris ${ }^{\mathrm{a}}$ \\ a Chemistry Department, Faculty of Sciences and Mathematics, Diponegoro University, Jalan Prof. Soedarto, Tembalang, Semarang \\ * Corresponding author: sriatun@live.undip.ac.id
}

\section{Article Info}

Keywords: Synthesis, Zeolite, ratio of $\mathrm{Si} / \mathrm{Al}$

\begin{abstract}
Synthesis of zeolite with variation of $\mathrm{Si} / \mathrm{Al}$ ratio and crystallization time with reflux heating method has been done. The Si/Al variations used were $25,50,75,100$. The purposes of this research were to obtain material from the reaction of sodium silicate and sodium aluminate with variation of $\mathrm{Si} / \mathrm{Al}$ and time of crystallization by reflux heating method and to characterize the synthesized material. The method used for crystallization was reflux at $100^{\circ} \mathrm{C}$ with variation of time between 1 to 7 days. The synthesis results in solid form with the composite component of a mixture of Hydrogen Sodium Alumium silicate compound, Sodium Aluminum silicate Hydrate and Sodium Hydrogen Aluminum Silicate Hydrate. The peaks of the Sodium Hydrogen Alumium silicate at $\mathrm{d}(\AA)$ were $4.88 \AA ; 4.36 \AA ; 2.47 \AA$. The peaks of Sodium Aluminum silicate Hydrate at d $(\AA)$ were $4.79(\AA) ; 4.63(\AA) ; 4.33(\AA)$. The peaks of Sodium Hydrogen Aluminum Silicate Hydrate at d $(\AA)$ were $5.33(\AA) ; 4.48(\AA)$; $3.97(\AA)$. The higher the Si/Al ratio $(25,50,75,100)$, the crystallinity decreases, while there was no significant difference caused by the variation of crystallization time of 1 and 7 days.
\end{abstract}

\section{Abstrak}

Telah dilakukan sintesis zeolit dengan variasi rasio Si/Al dan waktu kristalisasi dengan metode pemanasan refluks. Variasi Si/Al yang digunakan pada penelitian ini adalah 25, 50, 75, 100. Tujuan penelitian ini adalah memperoleh material hasil sintesis natrium silikat dan aluminat dengan variasi Si/Al dan waktu kristalisasi dengan metode pemanasan refluks serta karakterisasi material hasil sintesis. Metode yang digunakan untuk kristalisasi adalah pemanasan refluks pada suhu $100{ }^{\circ} \mathrm{C}$ dengan variasi waktu 1 dan 7 hari. Hasil sintesis berupa padatan dengan komponen penyusun/campuran senyawa Hydrogen Sodium Alumium silicate, Sodium Alumunium silicate Hydrate dan Sodium Hydrogen Alumunium Silicate Hydrate. Puncak-puncak Hydrogen Sodium Alumium silicate pada d $(\AA)$ adalah 4,88 $\AA$; 4,36 $\AA$; 2,47 $\AA$. Puncak-puncak Sodium Alumunium silicate Hydrate pada $\mathrm{d}(\AA)$ adalah 4,79 $(\AA) ; 4,63(\AA) ; 4,33(\AA)$. Puncak-puncak Sodium Hydrogen Alumunium Silicate Hydrate pada $\mathrm{d}(\AA)$ adalah $5,33(\AA) ; 4,48(\AA) ; 3,97(\AA)$. Pengaruh rasio Si/Al terhadap kristalinitas adalah semakin tinggi rasio $\mathrm{Si} / \mathrm{Al}(25,50,75,100)$, maka kristalinitas akan menurun serta tidak adanya perbedaan yang signifikan pada variasi waktu kristalisasi 1 dan 7 hari.

\section{Pendahuluan}

Zeolit merupakan senyawa aluminosilikat terhidrasi yang memiliki kerangka struktur tiga dimensi dan merupakan padatan kristalin dengan kandungan utama silikon, aluminium, dan oksigen serta dapat mengikat sejumlah molekul air di dalam porinya. Zeolit ada dua macam, yaitu zeolit alam dan zeolit sintetik. Zeolit alam semakin banyak dimanfaatkan sehingga jumlahnya semakin berkurang, zeolit alam memiliki 
beberapa kelemahan antara lain karena ketidakmurniaannya yang tinggi serta ukuran pori tidak seragam. Umumnya, zeolit alam seperti mordenite memiliki diameter pori 3.0-6.2 $\AA$ [1], sehingga kemampuan sebagai penyaring atau pemisah terhadap molekul-molekul yang berukuran besar sangat terbatas, oleh karena itu dilakukan sintesis zeolit.

Zeolit sintetik digunakan dalam industri kimia sebagai katalis, ion exchanger, dan adsorben, selain itu dikembangkan juga untuk mengatasi kelemahan dari zeolit alam, antara lain dengan mengatur pori-porinya sehingga lebih spesifik pemanfaatannya.

Zhang dkk. [2] mensintesis zeolit NaX menggunakan metode hidro-termal dengan variasi rasio $\mathrm{Si} / \mathrm{Al} \mathrm{1,5;2,0;2,9;} \mathrm{3,5;} \mathrm{dan} \mathrm{4,0.} \mathrm{Hasil} \mathrm{yang} \mathrm{diperoleh}$ adalah ukuran pori rata-rata pada rasio $\mathrm{Si} / \mathrm{Al} 1,5 ; 2,0$; 2,9; 3,5; dan 4,0 adalah 980, 836, 689, 548 dan $464 \mathrm{~nm}$. Thuadaija dan Nuntiyab [3] mensintesis zeolit dan memperoleh hasil bahwa pada rasio 3,25 mencapai fase zeolit NaX dengan kapasitas tukar kation 420 meq/100 gram dan luas permukaannya $398 \mathrm{~m}^{2}$ /gram.

\section{Metode Penelitian}

\section{Alat dan Bahan}

Peralatan gelas, labu alas bulat, kertas saring whatman 42, neraca analitik, $\mathrm{pH}$ meter, magnetic stirrer, hot plate, kondensor, termometer. Natrium Hidroksida $(\mathrm{NaOH})$ p.a, aquades $\left(\mathrm{H}_{2} \mathrm{O}\right)$, Natrium Silikat $\left(\mathrm{Na}_{2} \mathrm{SiO}_{3}\right)$, $\mathrm{HCl}$ dan $\mathrm{Al}(\mathrm{OH})_{3}$.

\section{Sintesis Zeolit}

Sebanyak 2 gr $\mathrm{NaOH}$ dilarutkan dalam $50 \mathrm{~mL}$ akuadest dan ditambahkan 1 gram $\mathrm{Al}(\mathrm{OH})_{3}$ dan menghasilkan larutan natrium aluminat. Untuk membuat variasi rasio Si/Al 25, 50, 75, 100 berturutturut ditambahkan natrium silikat sebanyak adalah 9,1; 18,$2 ; 27,3 ; 36,4$ gram pada larutan natrium aluminat dan diaduk sampai ter-bentuk gel. $\mathrm{pH}$ larutan diatur antara 11-12. Campuran kemudian direfluks pada suhu $100^{\circ} \mathrm{C}$ selama 1 dan 7 hari. Produk padatan yang dihasilkan dicuci dengan aquades sampai $\mathrm{pH}$ netral, kemudian dikeringkan dengan oven pada suhu $80^{\circ} \mathrm{C}$. Adapun karakterisasi hasil material menggunakan FTIR dan Difraktometer sinar - X.

\section{Hasil Dan Pembahasan}

Penelitian ini dilakukan dengan mensintesis zeolit dari natrium silikat dan natrium aluminat dengan metode refluks. Hasil yang diperoleh berupa padatan kristal. Padatan yang diperoleh dikarak-terisasi dengan FTIR dan XRD untuk mengetahui material yang terbentuk.

\section{Sintesis Zeolit}

Proses sintesis zeolit dilakukan dengan mereaksikan larutan natrium aluminat ke dalam natrium silikat. Sumber alumina dalam sintesis zeolit adalah natrium aluminat yang dibuat dari $\mathrm{Al}(\mathrm{OH})_{3}$ di tambahkan dengan $\mathrm{NaOH}$.
Reaksi yang terjadi pada proses ini adalah reaksi antara natrium silikat dengan natrium aluminat di dalam air akan membentuk silanol yang merupakan monomer pembentuk zeolit. Reaksi yang terjadi adalah:

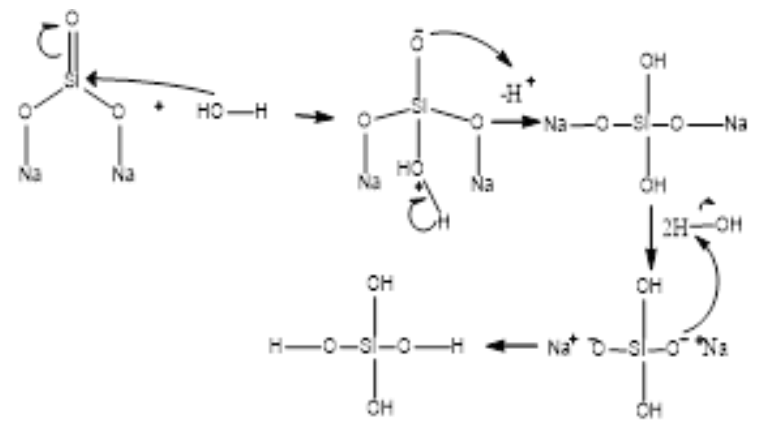

Gambar 1. Reaksi pembentukan silanol

Setelah silanol terbentuk selanjutnya dilakukan proses pendiaman (ageing) yang bertujuan untuk mengarahkan pada pemutusan monomer silika menjadi stuktur gel yang lebih kuat (gelasi). Pendiaman (ageing) dilakukan untuk menyem-purnakan pembentukan polimer zeolit dilakukan pada temperatur ruang selama 12 jam hingga terbentuk gel.

Kristalisasi dilakukan dengan metode hidrotermal selama 1 dan 7 hari pada suhu $100{ }^{\circ} \mathrm{C}$. Kristalisasi zeolit dipengaruhi oleh fase metastabil dengan terbentuknya gel dan fase stabil yaitu terbentuknya kristal zeolit dari gel tersebut. Pada tahap pembentukan kristal, gel amorf akan mengalami penataan ulang pada strukturnya oleh adanya pemanasan sehingga dapat terbentuk embrio inti kristal [4].

\section{Karakterisasi Material Hasil dengan FTIR}

Karakterisasi menggunakan FTIR bertujuan untuk mengetahui gugus fungsi penyusun kerangka zeolit. Analisa FTIR dilakukan mulai dari bilangan gelombang 4000-400 $\mathrm{cm}^{-1}$, pada rentang bilangan gelombang tersebut terdapat gugus-gugus fungsi serta sidik jari yang dimiliki oleh zeolit. Daerah serapan sekitar $1100-700 \mathrm{~cm}^{-1}$ merupakan sidik jari zeolit dimana terdapat vibrasi Si-O dan Al-O. Hasil analisis FTIR sampel dapat dilihat pada gambar 2 dan gambar 3. Produk ini mempunyai serapan yang kuat pada bilangan gelombang $1250-950 \mathrm{~cm}^{-1}$ dan $850-650$ $\mathrm{cm}^{-1}$ sehingga dapat diasumsikan bahwa keempat hasil sintesis telah terbentuk zeolit. 
(6)

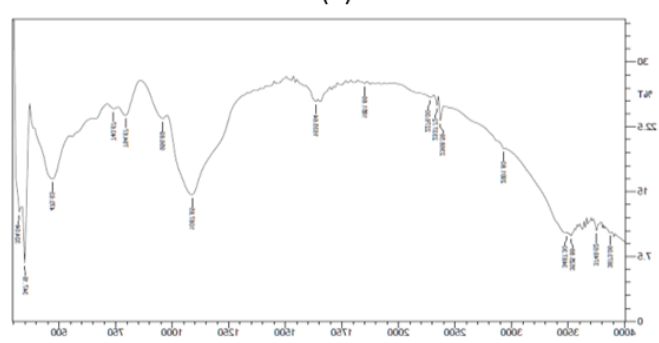

(d)

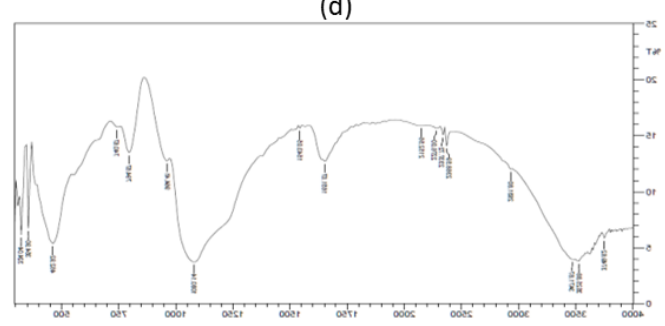

(ว)

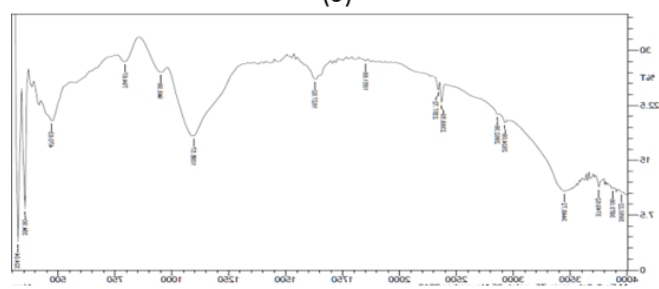

(b)

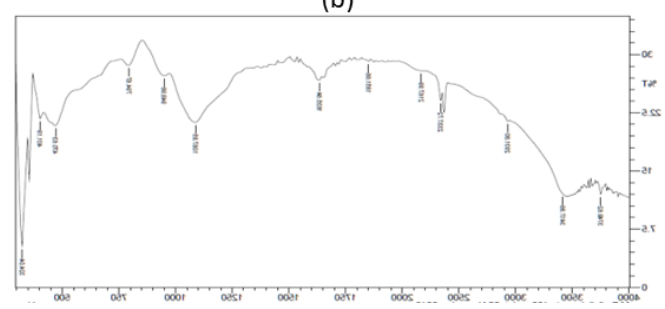

Gambar 2.Spektra FTIR material hasil sintesis (Y-1D), (Y-2D), (Y-3D), (Y-4D) berturut - turut dengan variasi rasio $\mathrm{Si} / \mathrm{Al}$ 25,50,75,100 waktu kristalisasi 1 hari. (a)

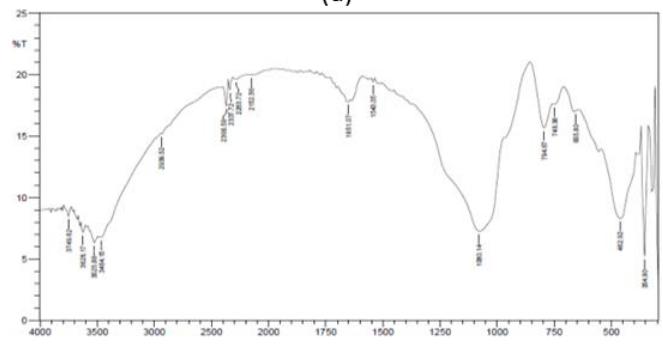

(b)

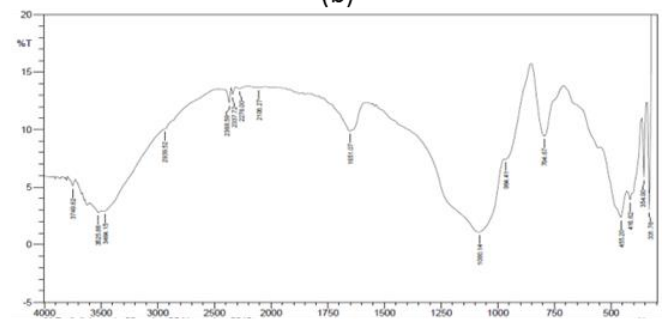

(c)

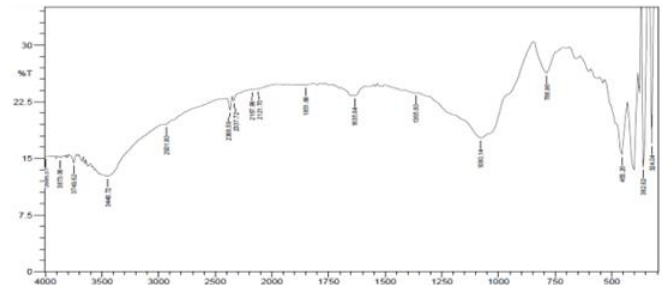

(d)

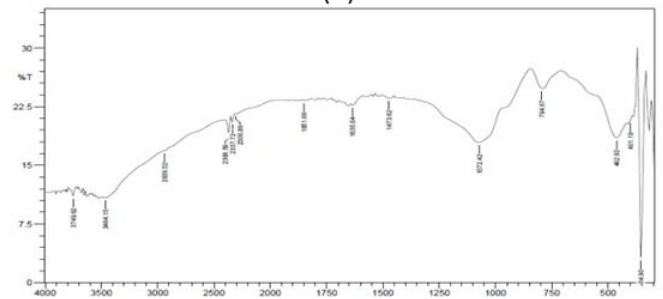

Gambar 3. Spektra FTIR material hasil sintesis (a) Z1D, (b) Z-2D, (c) Z-3D, (d) Z-4D berturut-turut dengan variasi rasio $\mathrm{Si} / \mathrm{Al}$ 25,50,75,100 waktu kristalisasi 7 hari

Penjelasan pada gambar 2 dan gambar 3 diperoleh kesimpulan bahwa sintesis zeolit dengan variasi rasio Si/Al 25 dan 50 serapan pada bilangan gelombang 1250$950 \mathrm{~cm}^{-1}$, bilangan gelombang $850-650 \mathrm{~cm}^{-1}$ dan $500-$ $420 \mathrm{~cm}^{-1}$ sangat tajam dibandingkan dengan variasi rasio Si/Al 75 dan 100 yang ditandai dengan adanya gugus fungsi yang spesifik yakni $\mathrm{Si}-\mathrm{O}$ dan $\mathrm{Al}-\mathrm{O}$, dan $\mathrm{OH}$. Penjelasan ini dilihat material hasil sintesis dengan variasi 25 dan 50 pada puncak-puncak tertentu yang memiliki intensitas yang tinggi, luas area sebesar 522,$424 ; 64,701$; dan 143,688. Bilangan gelombang yang memiliki serapan paling tajam adalah bilangan gelombang 462,92; 794,67 dan 1080,14 $\mathrm{cm}^{-1}$ serta gugus -OH yang terdapat pada bilangan gelombang 1651,07 ; 3464,15 dan $3471 \mathrm{~cm}^{-1}$.

Karakterisasi Material Hasil dengan Difraksi Sinar-X (XRD)

Difraksi sinar-X merupakan suatu metode analisa kualitatif yang berfungsi untuk mengalisa struktur, dan ukuran kristal suatu padatan. Karakterisasi menggunakan XRD akan diamati difraktogram sampel dengan variasi rasio Si/Al 25, 50, 75 dan 100 pada waktu kristalisasi 1 dan 7 hari. Analisis menggunakan XRD 
digunakan sampel dengan rasio $\mathrm{Si} / \mathrm{Al} 25$ dan 50 dikarenakan merupakan sampel yang terbaik dari analisis FTIR. Data FTIR yang diperoleh, sampel yang memiliki serapan dengan intensitas kuat dan runcing pada sampel dengan variasi rasio $\mathrm{Si} / \mathrm{Al} 25$ dan 50 dengan waktu kristalisasi 1 dan 7 hari.

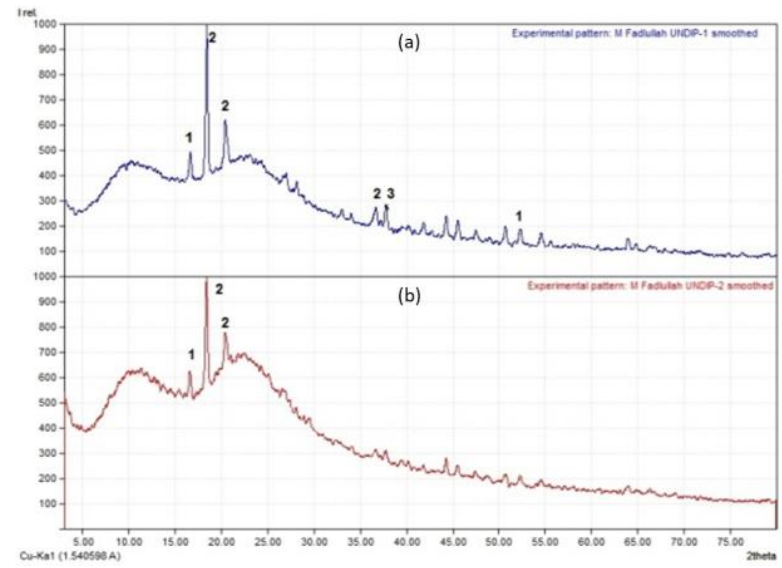

Gambar 4. Difraktogram XRD dengan variasi rasio $\mathrm{Si} / \mathrm{Al}$ (a) 25 Y-1D dan (b) 50 Y-2D dengan waktu kristalisasi 1 hari

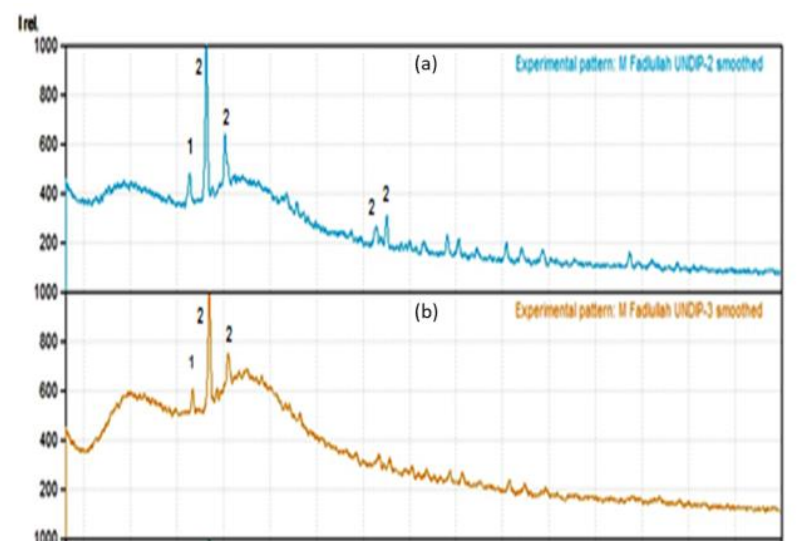

Gambar 5. Difraktogram XRD dengan variasi rasio Si/Al (a) 25 Y-1D, dan (b) 50 Y-2D dengan waktu kristalisasi 7 hari

Berdasarkan difraktogram pada gambar 4 dan gambar 5, sampel terdapat pada daerah $d(\AA)$ yang hampir sama, sehingga diperkirakan material yang dihasilkan pada sampel ini sama yaitu diperkirakan berupa campuran: Hydrogen Sodium Alumium silicate (H1.7 Nao.6 Al2.3 Si 93.7 0192), Sodium Alumunium silicate Hydrate (Al2 Nao.18 024.29 Si10.6 .xH2O), dan Sodium Hydrogen Alumunium Silicate Hydrate (Na15 H2.71 Al1.21 (Al7.86 Si 28.14 072. $2 \mathrm{H}_{2} \mathrm{O}$ ).

\section{Kesimpulan}

Sintesis zeolit telah berhasil dilakukan, kondisi optimum dicapai pada rasio $\mathrm{Si} / \mathrm{Al}$ 50. Semakin tinggi rasio $\mathrm{Si} / \mathrm{Al}(25,50,75,100)$, maka kristalinitas akan menurun serta tidak ada perbedaan yang signifikan pada variasi waktu kristalisasi 1 dan 7 hari. Produk zeolit yang terbentuk adalah Hydrogen Sodium Alumium silicate, Sodium Alumunium silicate Hydrate, dan Sodium Hydrogen Alumunium Silicate Hydrate.

\section{Daftar Pustaka}

[1] D.W. Breck, Zeolite molecular sieves: structure, chemistry, and use, Wiley, 1973.

[2] Xu Zhang, Dingxing Tang, Min Zhang, Renchun Yang, Synthesis of NaX zeolite: Influence of crystallization time, temperature and batch molar ratio $\mathrm{SiO}_{2} / \mathrm{Al}_{2} \mathrm{O} 3$ on the particulate properties of zeolite crystals, Powder Technology, 235, (2013) 322328 http://dx.doi.org/10.1016/j.powtec.2012.10.046

[3] Pattaranun Thuadaija, Apinon Nuntiyab, Effect of the $\mathrm{SiO}_{2} / \mathrm{Al}_{2} \mathrm{O}_{3}$ ratio on the synthesis of Na-x zeolite from Mae Moh fly ash, Science Asia, 38, (2012) 295300 http://dx.doi.org/10.2306/scienceasia15131874.2012.38.295

[4] SK Hadi, Pembuatan dan Karakterisasi Zeolit A dari Sekam Padi, Kimia, Universitas Gadjah Mada, Yogyakarta 